\title{
Adverse effects of spinal manipulation: a systematic review
}

\author{
E Ernst
}

J R Soc Med 2007; 100:330-338

\section{SUMMARY}

Objective To identify adverse effects of spinal manipulation.

Design Systematic review of papers published since 2001.

Setting Six electronic databases.

Main outcome measures Reports of adverse effects published between January 2001 and June 2006. There were no restrictions according to language of publication or research design of the reports.

Results The searches identified 32 case reports, four case series, two prospective series, three case-control studies and three surveys. In case reports or case series, more than 200 patients were suspected to have been seriously harmed. The most common serious adverse effects were due to vertebral artery dissections. The two prospective reports suggested that relatively mild adverse effects occur in $30 \%$ to $61 \%$ of all patients.

The case-control studies suggested a causal relationship between spinal manipulation and the adverse effect. The survey data indicated that even serious adverse effects are rarely reported in the medical literature.

Conclusions Spinal manipulation, particularly when performed on the upper spine, is frequently associated with mild to moderate adverse effects. It can also result in serious complications such as vertebral artery dissection followed by stroke. Currently, the incidence of such events is not known. In the interest of patient safety we should reconsider our policy towards the routine use of spinal manipulation.

Spinal manipulation or adjustment is a manual treatment where a vertebral joint is passively moved between the normal range of motion and the limits of its normal integrity, though a universally accepted definition does not seem to exist. ${ }^{1}$ It is occasionally used by osteopaths, physiotherapists and physicians, and it is the hallmark treatment of chiropractors. Practically all chiropractors use spinal manipulation regularly to treat low back and other musculoskeletal pain. ${ }^{2}$ It often involves a high velocity thrust, a technique in which the joints are adjusted rapidly, often accompanied by popping sounds. This results in

Complementary Medicine, Peninsula Medical School, Universities of Exeter \& Plymouth, 25 Victoria Park Road, Exeter EX2 4NT, UK transient stretching of joint capsules which, according to chiropractic belief, resets the position of the spinal cord and nerves, allowing the nervous system to function optimally and improving the body's biomechanical efficiency. ${ }^{3}$ The thrust is exerted through either a long lever arm, in which force is applied distant from the joint, or a short lever arm, when force is applied close to the joint. Many experts see spinal manipulation as an effective form of treating back pain: ${ }^{4}$ the evidence from randomized clinical trials (RCTs), however, remains contradictory and often unconvincing. ${ }^{5}$ For conditions other than back pain, there is no good evidence for the effectiveness of spinal manipulation. ${ }^{5}$

Many authors have voiced doubt about the safety of spinal manipulation. A particular concern is stroke after upper spinal manipulation. The systematic review by Ernst and Stevinson, published in 2002, summarized safety data available up to 2001.6 Since then, an abundance of new evidence has emerged. The aim of this article is therefore to identify adverse effects of spinal manipulation published since 2001.

\section{METHODS}

Computerized literature searches were performed using MEDLINE (PubMed), EMBASE, Amed, CINHAL, the British Nursing Index and the Cochrane Library up to June 2006. The search terms used were 'adverse effects', 'adverse events', 'arterial injury', 'cervical manipulation', 'chiropractic', 'complications', 'manual therapy', 'osteopathy', 'risk', 'safety', 'spinal manipulation', 'stroke', 'vascular accident', and 'vertebral artery dissection'. In addition, our departmental files were searched, and other experts were consulted. The bibliographies of relevant papers were scanned for pertinent articles. All reports, irrespective of language of publication, which contained data about risks associated with spinal manipulation were included, regardless of the profession of the therapist or the research methodology used for the report. Articles from 2000 or earlier, dual publications of the same material ${ }^{7}$ and cases of spinal manipulation for non-therapeutic purposes $^{8}$ were excluded. All relevant reports were obtained in full. Key data were extracted by the author according to predefined criteria, tabulated and also described narratively. 


\section{RESULTS}

\section{Case reports}

The search strategy located 28 articles reporting a total of 32 case reports (Tables 1 and 2). In 22 cases (published in 20 articles) the therapists were chiropractors (Table 1), ${ }^{9-28}$ while in 10 cases (published in nine articles) they were other health-care professionals (Table 2). ${ }^{13,29-36}$ In the majority of cases, the problem related to upper spinal manipulations including rotational movements. The patients were mostly young healthy individuals treated for benign, self-limiting conditions such as neck pain or headache. There was no clear over-representation of one sex over another. Dissection of the vertebral arteries was the most common problem; other complications included dural tear, oedema, nerve injury, disc herniation, haematoma and bone fracture. The symptoms were frequently life-threatening, though in most cases the patient made a full recovery. In the majority of cases, spinal manipulation was deemed to be the probable cause of the adverse effect.

\section{Retrospective case series}

Haldemann et al. analysed 64 cases in which a cerebrovascular ischaemic event had occurred after spinal manipulation. ${ }^{37}$ All cases had been referred to Haldemann for medico legal review during a 16-year period, and none had previously been reported in the medical literature. The patients were predominantly women (mean age 39 years) who had consulted a chiropractor for neck pain or headache. In 48 cases, the onset of the stroke was within 30 minutes after spinal manipulation. The authors were unable to identify any risk factors that would discriminate high risk from low risk patients. Neurological status one year after the stroke was available for 46 patients: eight had made a full recovery, two had died, and the rest were still suffering from persistent neurological deficits.

Young and Chen described nine patients who were admitted for acute vertigo after spinal manipulation by chiropractors or practitioners of Traditional Chinese Medicine. ${ }^{38}$ Magnetic resonance angiography showed that the clinical symptoms were due to vertebral artery occlusion $(n=1)$, stenosis $(n=1)$, slow blood flow $(n=1)$ or associated with normal findings $(n=6)$. The average time between spinal manipulation and onset of symptoms was 17 hours (range 1-24 hours). All patients made a full recovery after treatment.

Hansis et al. published an analysis of 57 patients who had been referred during 28 years to the North Rhine General Medical Council for alleged malpractice. ${ }^{39}$ In 20 patients who had experienced a disc prolapse after spinal manipulation, the Council attested five instances of malpractice. In six cases of bone fractures, the Council attested one instance of malpractice. In nine cases of cerebrovascular accidents, seven of which were due to dissection of the vertebral artery, the Council attested malpractice four times. In 22 instances, patients had complained that spinal manipulation had no effect or had worsened the presenting condition: the Council attested malpractice in two of them.

Oppenheim et al. conducted a chart review of 18 patients (nine men and nine women aged 31-72 years) who suffered non-vascular adverse effects after receiving spinal manipulation by chiropractors. ${ }^{40}$ The injuries occurred in the cervical (33\%), thoracic (22\%) and lumbar spine $(44 \%)$. In nine cases, they were associated with spinal cord injuries (myelopathy, quadriparesis, central cord syndrome or paraparesis); two patients experienced cauda equina syndrome; six patients developed radiculopathy; and three patients had pathological fractures related to cancer which the chiropractors had failed to diagnose. Sixteen patients required surgery; half of them subsequently made an excellent recovery, and $31 \%$ a good recovery.

Reuter et al. reported 36 cases of vertebral artery dissection seen within three years in 13 neurological centres. ${ }^{41}$ On admission, 30 of these patients had neurological deficits; on discharge this figure had decreased to 18. Spinal manipulation had been administered by orthopaedic surgeons (50\%), physiotherapists (14\%), chiropractors $(11 \%)$ or other health-care professionals. In $14 \%$ of all cases, the onset of symptoms was during treatment, while in a further $12 \%$ it was within one hour. All patients had been treated with spinal manipulation for benign conditions such as neck or back pain.

\section{Prospective case series}

Cagnie et al. invited 59 Belgian physiotherapists to recruit a total of 465 new patients treated by them with spinal manipulation. ${ }^{42}$ All patients were subsequently asked to complete a questionnaire about adverse effects. $61 \%$ of all patients reported at least one adverse effect, most of which were mild and transient, such as headache $(20 \%)$, stiffness (20\%), local discomfort (15\%), radiating discomfort (12\%) and fatigue $(12 \%) .63 \%$ of these patients noted more than one symptom. In $61 \%$, the problems had started within four hours after manipulation, and 64\% had resolved within 24 hours. $21 \%$ of post-manipulative effects were experienced as 'severe', and $27 \%$ of patients felt impaired in their daily activities. No complications with long-lasting consequences were reported.

Hurwitz et al. reported adverse effects documented in a randomized controlled trial comparing spinal manipulation with spinal mobilization as treatments of neck pain. ${ }^{43}$ Of 280 patients, 30\% reported at least one adverse effect. Patients receiving spinal manipulation were more likely to experience adverse effects than patients treated with 


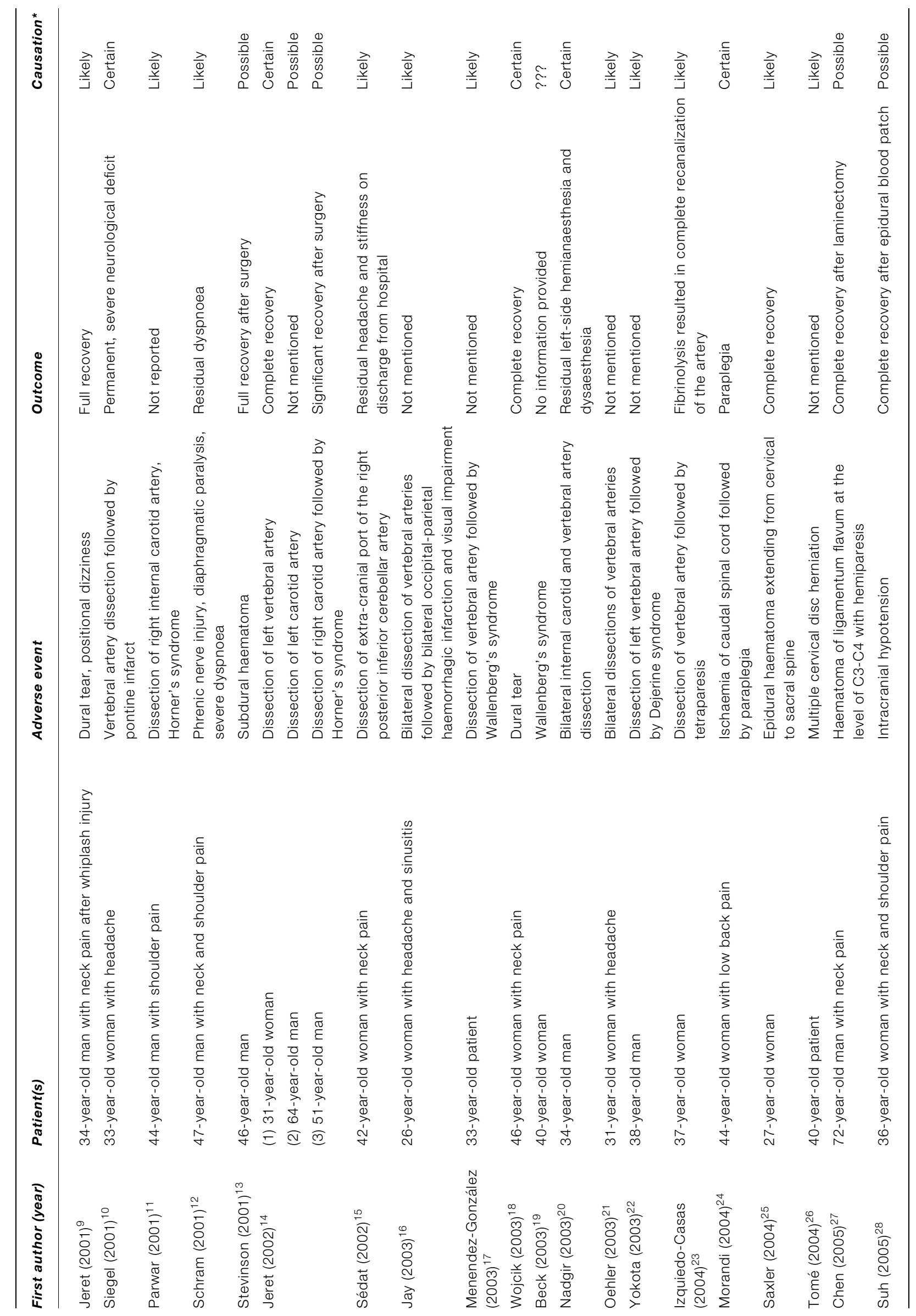




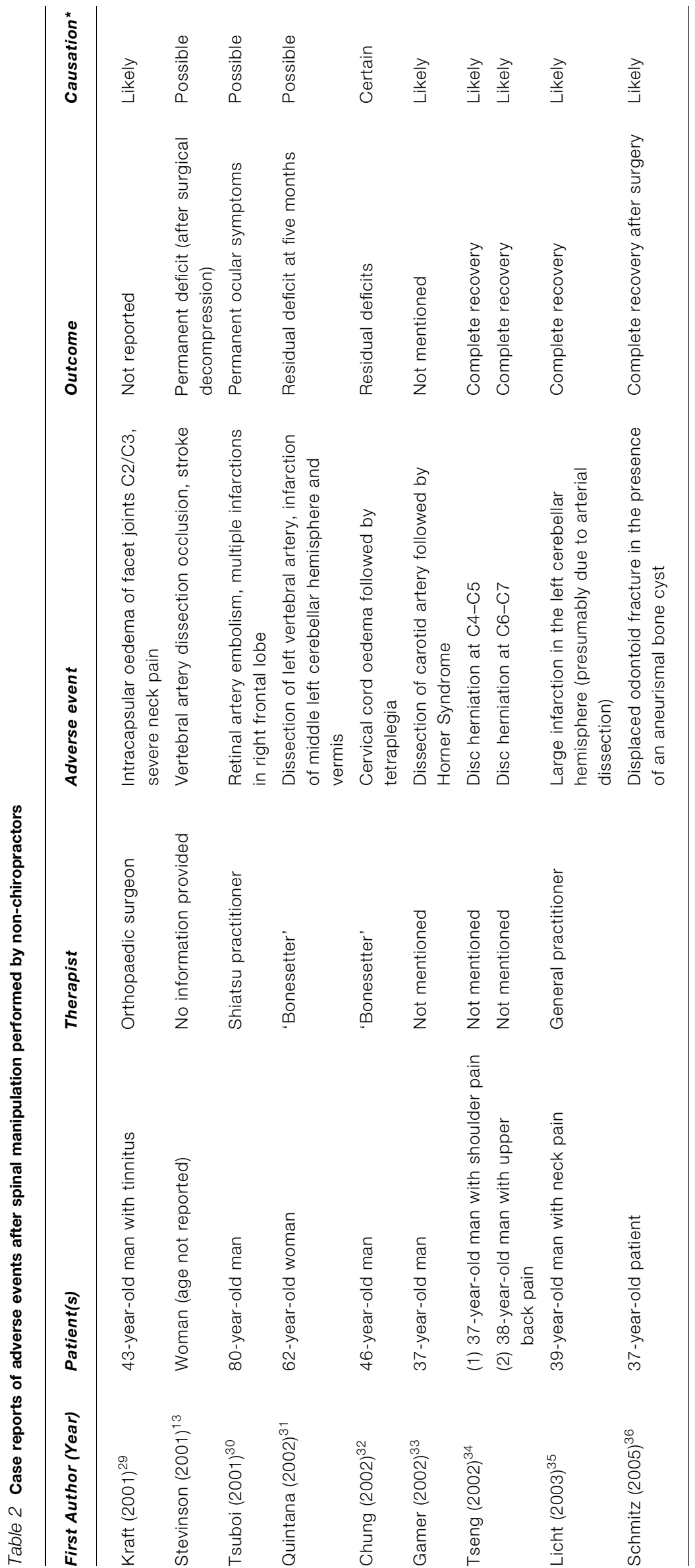


mobilization, a more gentle manual technique preferred by many osteopaths. The most frequently noted adverse effects were increase of pain, headache, tiredness and radiating pain. $80 \%$ of the adverse effects began with 24 hours after treatment and were of moderate or medium severity. No serious complications were noted.

\section{Case-control studies}

Dziewas et al. studied 126 patients with carotid or vertebral artery dissections. ${ }^{44}$ Compared to patients with carotid artery dissections, patients with vertebral artery dissections more frequently reported having previously had chiropractic upper spinal manipulation (6\% versus 30\%). Bilateral vertebral artery dissection was also significantly related to a preceding chiropractic manipulation. Five cases of carotid artery dissection were associated with prior spinal manipulation, and all had a good clinical outcome. Fourteen cases of vertebral artery dissection were linked to spinal manipulation, of which ten had a good, three a moderate and one a poor clinical outcome. The authors concluded that 'this study emphasizes the potential dangers of chiropractic manipulation of the cervical spine.'

Rothwell et al. studied hospital records in Ontario to identify all cases of vertebrobasilar accidents within a fiveyear period. ${ }^{45}$ They found 582 such cases and matched them by age and sex to four controls each who had no history of stroke. In patients younger than 45 years, the odds of having a vertebrobasilar accident within one week of visiting a chiropractor were increased by a factor of five. In this age group, cases were five times more likely to have had more than three chiropractic consultations with a cervical diagnosis in the month before the event.

Smith et al. conducted blinded chart review and face-toface interviews with 51 patients under the age of 60 years from two stroke centres in the USA. ${ }^{46}$ They were age- and sex-matched to 100 controls. In univariate analysis, cases were more likely than controls to have had spinal manipulation within 30 days of the vascular accident (14\% versus $3 \%)$. In multivariate analysis, vertebral arterial dissections were independently associated with spinal manipulations within 30 days (odds ratio [OR] 6.62). For carotid dissection, no significant association was noted. The authors conclude that spinal manipulation 'is independently associated with vertebral arterial dissection, even after controlling for neck pain.'

A systematic review of case control studies of potential risk factors for cervical artery dissection found 'a strong association for manipulative therapy' (OR 3.8, 95\% confidence interval [CI] 1.3-11). ${ }^{47}$ However, these results were based only on two studies. The authors therefore urge caution until further evidence becomes available.

\section{Surveys}

Adams and Sim posted a questionnaire about adverse effects of spinal manipulation to 300 UK manipulative therapists. ${ }^{48}$ Of the respondents, 129 used spinal manipulation. Anxiety about complications was a prominent reason for not using manipulation. Cervical rotary manipulations were thought by some respondents to be potentially dangerous. Overall, respondents felt 'uncertain as to whether its benefits outweighed its risks.' 48

Dupeyron et al. surveyed 240 French doctors with a diploma in 'manual medicine' asking them to provide details of all complications after spinal manipulation during the preceding two years. ${ }^{52} 93$ such cases were disclosed, none of which had previously been reported in the medical literature. $69 \%$ of them related to radiculopathies and $15 \%$ to cerebrovascular accidents, and $53 \%$ of the problems became symptomatic within 24 hours after treatment.

Egizii et al. posted questionnaires to 234 French doctors with 'Manual Medicine' or 'Osteopathy' diplomas from Strasbourg University between 1985 and 2002. ${ }^{49}$ Responses were obtained from 140 physicians. Most of them used spinal manipulation in their daily practice. $24 \%$ of the respondents stated that they had caused one or more adverse effects through spinal manipulation; no further details were supplied.

\section{DISCUSSION}

The case reports (Tables 1 and 2) confirm previous reports ${ }^{6}$ associating upper spinal manipulation with a range of complications. The most serious problems, which some experts now describe as 'well-recognized',22 are vertebral artery dissections due to intimal tearing as a result of overstretching the artery during rotational manipulation. This seems to occur most commonly at the level of the atlantoaxial joint. ${ }^{20}$ Intimal injury can be followed by intramural bleeding or pseudoaneurysm formation, which can result in thrombosis, embolism ${ }^{20}$ or arterial spasm. ${ }^{22}$

The retrospective case series (Table 3) confirm that spinal manipulation is associated with risks such as vascular accidents and non-vascular complications. Such adverse effects are being reported from several countries and often have serious consequences. The therapists involved are mostly chiropractors; this predominance is probably due to the fact that these therapists use spinal manipulation more frequently than other practitioners. Most of the incidents reported in case series or surveys had not been previously reported, indicating that under-reporting may frequently be high.

The two prospective case series ${ }^{42,43}$ corroborate the results from several earlier investigations ${ }^{50}$ showing that mild to moderate adverse effects occur in a large proportion of patients receiving spinal manipulation. These adverse 


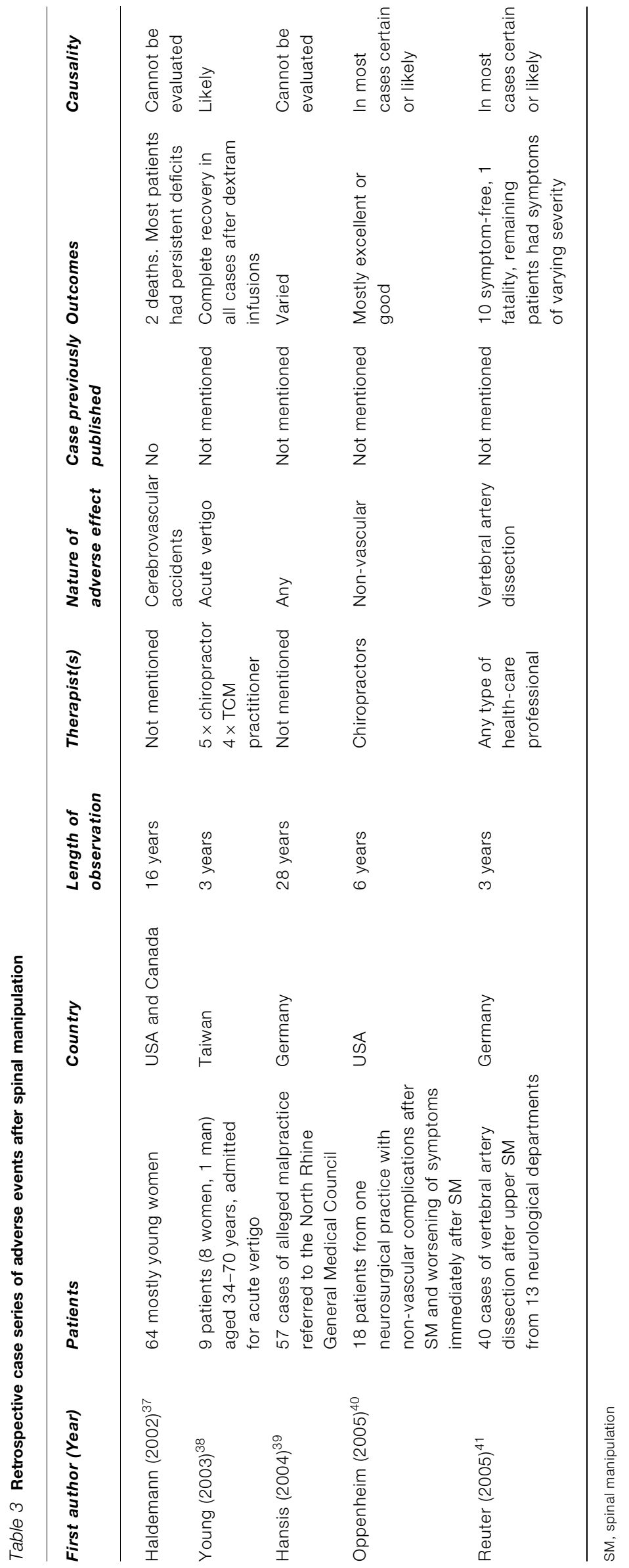


effects are transient and non-serious but nevertheless seriously affect many patients. ${ }^{42,50}$ Risk-benefit evaluations of spinal manipulation must therefore account not just for serious complications but also for such adverse events.

Case-control and other studies confirm that upper spinal manipulation is associated with risks ${ }^{4-47}$ and that spinal manipulation is an independent risk factor for vertebral artery dissection. ${ }^{46}$ Many chiropractors insist that a causal link is questionable or unlikely, as the early signs of arterial dissections include neck pain, which could be the reason for a patient to consult a chiropractor, therefore these possible associations could be false. ${ }^{23,51}$ Smith et al. tried to account for this particular confounder and still found spinal manipulation to be a risk factor. ${ }^{46}$

The three surveys disclose more complications. They suggest that many therapists are now becoming aware of the risks of spinal manipulation. ${ }^{48,49}$ Two of the surveys ${ }^{49,52}$ also confirm that under-reporting is frequently close to $100 \%$.

It seems unfair to assess the risk of spinal manipulation as practised by well-trained chiropractors alongside that associated with untrained therapists (Tables 1 and 2). Chiropractors may argue that it takes years of experience to learn the fine psychomotor control required for skilled manipulations. Certainly skill and experience are important, and it is relevant to differentiate between different professions, as done in Tables 1 and 2. On the other hand, skill is a quality not easily controlled for in such research; even some chiropractors may be more skilled than others. Moreover, this review is aimed at evaluating the risk of an intervention (spinal manipulation) and not that of a profession (chiropractic). In fact, this review shows that the implicated practitioners are not only chiropractors but also surgeons, shiatsu practitioners, 'bonesetters' and general practitioners (Table 2).

Collectively, these data suggest that spinal manipulation is associated with frequent, mild and transient adverse effects as well as with serious complications which can lead to permanent disability or death. Yet causal inferences are, of course, problematic. Vascular accidents may happen spontaneously or could have causes other than spinal manipulation. A temporal relationship is insufficient to establish causality, and recall bias can further obscure the truth. Moreover, denominators are rarely available. Consequently the frequency of serious adverse effects is currently unknown. Estimates by chiropractors vary (e.g. 6.4 per 10 million manipulations of the upper spine and 1 per 100 million manipulations of the lower spine). ${ }^{53}$ These figures, however, may be over-optimistic. Retrospective investigations have repeatedly shown that under-reporting is close to $100 \%{ }^{13,52}$ This level of under-reporting would render such estimates nonsensical. At present, there is no sufficiently large and rigorous prospective study to generate reliable incidence figures; previous studies have failed to investigate those patients which were lost at follow-up. This could be the subgroup which has been harmed. It is therefore essential that future studies follow up close to $100 \%$ of the initial patient sample.

The effectiveness of spinal manipulation for most indications is less than convincing. ${ }^{5}$ A risk-benefit evaluation is therefore unlikely to generate positive results: with uncertain effectiveness and finite risks, the balance cannot be positive. Cautious attitudes towards upper spinal manipulation are therefore becoming more widespread: 'special caution should be exercised when performing firstline cervical manipulation and simple, honest and easily understandable information about there risks should be included when informed consent is obtained.' 54

Some therapists have started advocating screening patients for risk factors before treatment. ${ }^{55-57}$ Based on cadaver studies of human vertebral arteries, Cagnie et al. ${ }^{58}$ have suggested that, in the presence of arteriosclerotic changes, the stretching and compression effects of rotational manipulation may constitute a risk factor for vascular accidents. These authors concluded that 'therapists should avoid manipulative techniques at all levels of the cervical spine in the presence of any indirect sign of arteriosclerotic disease or in the presence of calcified arterial walls or tortuosities of the vessel.' 58 Others have suggested that high homocystein levels constitute a risk factor for arterial dissection. ${ }^{59}$ Spinal manipulation might therefore be contraindicated in such individuals. The effectiveness of screening has, however, not been convincingly demonstrated. The chiropractic profession tends to downplay the risks: 'chiropractic services are safe'; 60 'the healthy vertebral artery is not at risk from properly performed chiropractic manipulative procedures.' 61 Others argue that 'the occurrence of cerebrovascular accidents in the chiropractic population is $0.000008 \%$ ', ${ }^{62}$ that causality is not proven or even unlikely, ${ }^{61,63-66}$ that other interventions are more risky (see below), ${ }^{67}$ that the mechanical forces employed for spinal manipulation are too low to cause injury, ${ }^{68}$ or that there is a ploy from the medical establishment to sideline chiropractors. ${ }^{69-71}$ In the light of the evidence summarized above, such attitudes do not seem to be in the best interest of patients.

It is, of course, important to present any risk-benefit assessment fairly and in the context of similar evaluations of alternative therapeutic options. One such option is drug therapy. The drugs in question-nonsteroidal anti-inflammatory drugs (NSAIDs) - cause considerable problems, for example gastrointestinal and cardiovascular complications. ${ }^{72,73}$ Thus spinal manipulation could be preferable to drug therapy. But there are problems with this line of argument: the efficacy of NSAIDs is undoubted but that of spinal manipulation is 
not, and moreover, the adverse effects of NSAIDs are subject to post-marketing surveillance while those of spinal manipulation are not. Thus we are certain about the risks and benefits of the former and uncertain about those of the latter. Finally, it should be mentioned that other therapeutic options (e.g. exercise therapy or massage) have not been associated with significant risks at all.

This systematic review has several limitations. Even though the search strategy was thorough, some relevant published articles might have been missed. High levels of under-reporting or recall bias might distort the overall picture generated. Publication bias could have exerted a similar effect. For instance, it is possible that journals of complementary medicine are unlikely to publish findings which might be considered 'negative'. ${ }^{74}$

In conclusion, spinal manipulation, particularly when performed on the upper spine, has repeatedly been associated with serious adverse events. Currently the incidence of such events is unknown. Adherence to informed consent, which currently seems less than rigorous, ${ }^{75}$ should therefore be mandatory to all therapists using this treatment. Considering that spinal manipulation is used mostly for self-limiting conditions and that its effectiveness is not well established, ${ }^{5}$ we should adopt a cautious attitude towards using it in routine health care.

Competing interests None declared.

Funding None.

Ethical approval Not required.

Guarantor EE.

\section{REFERENCES}

1 Vernon H, Mrozek J. A revised definition of manipulation. J Manip Physiol Ther 2005;28:68-72

2 Hurwitz EL, Coulter ID, Adams AH, Genovese BJ, Shekelle PG. Use of chiropractic services from 1985 through 1991 in the United States and Canada. Am J Public Health 1998;88:771-6

3 Segan C. Dictionary of Alternative Medicines. Stamford, CT: Appleton and Lange: 1998

4 Ernst E, Pittler MH. Experts' opinions on complementary/alternative therapies for low back pain. J Manip Phys Ther 1999;22:87-90

5 Ernst E, Canter P. A systematic review of systematic reviews of spinal manipulation. J Roy Soc Med 2006;99:192-6

6 Stevinson C, Ernst E. Risks associated with spinal manipulation. Am J Med 2002;112:566-70

7 Haldeman S, Kohlbeck FJ, McGregor M. Stroke, cerebral artery dissection, and cervical spine manipulation therapy. J Neurol 2002; 249:1098-104

8 Panagariya A, Kumawat BL, Singh R, Sukhani P. Total unilateral medullary syndrome - a rare complicaton of chiropractic manipulation. J Assoc Physicians India 2004;52:556
9 Jeret JS. More complications of spinal manipulation. Stroke 2001;32:1136-7

10 Siegel D, Neiders T. Vertebral artery dissection and pontine infarction after chiropractic manipulation. Am J Emerg Med 2001;19:172-3

11 Parwar BL, Fawzi AA, Arnold AC, Schwartz SD. Horner's syndrome and dissection of the internal carotid artery after chiropractic manipulation of the neck. Am J Ophthalmol 2001;131:523-4

12 Schram DJ, Vosik W. Diaphragmatic paralysis following cervical chiropractic manipulation: case report and review. Complementary/ Alternative Medicine for Asthma 2001;119:638-40

13 Stevinson C, Honan W, Cooke B, Ernst E. Neurological complications of cervical spine manipulation. J Roy Soc Med 2001;94:107-10

14 Jeret JS, Bluth M. Stroke following chiropractic manipulation. Report of three cases and review of the literature. Cerebrovasc Dis 2002; 13:210-3

15 Sédat J, Dib M, Mahagne MH, Lonjon M, Paquis P. Stroke after chiropractic manipulation as a result of extracranial postero-inferior cerebellar artery dissection. J Manipulative Physiol Ther 2002;25:588-90

16 Jay WM, Shah MI, Schneck MJ. Bilateral occipital-parietal hemorrhagic infarctions following chiropractic cervical manipulation. Semin Ophthalmol 2003;18:205-9

17 Menendez-Gonzalez M, Garcia C, Suarez E, Fernandez-Diaz D, Blazquez-Menes B. Sindrome de Wallemberg secundario a diseccion de la arteria vertegral por manipulacion quiropractica. Rev Neurol 2003;37:837-9

18 Wojcik W, Pawlak JK, Knaus R. Doctor! I can't stand the noise in my ear! J Neurol Neurosurg Psychiatry 2003;74:55-9

19 Beck J, Raabe A, Seifert V. Intracranial hypotension after chiropractic manipulation of the cervical spine. I Neurol Neurosurg Psychiatry 2003;74:820-6

20 Nadgir RN, Loevner LA, Ahmed T, Chalela J, Slawek K, Imbesi S. Simultaneous bilateral internal carotid and vertebral artery dissection following chiropractic manipulation: case report and review of the literature. Neuroradiol 2003;45:311-4

21 Oehler J, Gandjour J, Fiebach J, Schwab S. Beidseitge A. Vertebralisdissektion nach chiropraktischer Behandlung. Orthopade 2003;32: 911-3

22 Yokota J, Amakusa Y, Tomita Y, Takahashi S. The medial medullary infarction (Dejerine syndrome) following chiropractic neck manipulation. No To Shinkei 2003;55:121-5

23 Izquierdo-Casas J, Soler-Singla L, Vivas-Diaz E, Balaguer-Martinez E, Sola-Martinez T, Guimaraens-Martinez L. Diseccion vertebral como causa del sindrome de enclaustramiento y opciones terapeuticas con fibrinolisis intraarterial durante la fase aguda. Rev Neurol 2004; 38: $1139-41$

24 Morandi X, Riffaud L, Houedakor J, Amlashi SFA, Brassier G, Gallien P. Caudal spinal cord ischemia after lumbar vertegral manipulation. Joint Bone Spine 2004;71:334-7

25 Saxler G, Barden B. Extensive spinal epidural hematoma-an uncommon entity following cervical chiropractic manipulation. $Z$ Orthop Ihre Grenzgeb 2004;142:79-84

26 Tome F, Barriga A, Espejo L. Herniacion discal multiple tras manipulatcion quiropractica cervical. Rev Med Univ Navarra 2004;48:39-41

27 Chen H-C, Hsu P-W, Lin C-Y, Tzaan W-C. Symptomatic hematoma of cervical ligamentum flavum. Spine 2005;30:E489-E491

28 Suh S-I, Koh S-B, Choi E-J, et al. Intracranial hypotension induced by cervical spine chiropractic manipulation. Spine 2005;30:E340-E342

29 Kraft CN, Conrad R, Vahlensieck M, Perlick L, Schmitt O, Dietrich O. Non-cerebrovascular complication in chirotherapy manipulation of the cervical vertebrae. Z Orthop Grenzgeb 2001;139:8-11

30 Tsuboi K. Retinal and cerebral artery embolism after 'Shiatsu' on the neck. Stroke 2001;32:2441 
31 Quintana JG, Drew EC, Richtsmeier TE, Davis LE. Vertebral artery dissection and stroke following neck manipulation by Native American healer. Neurol 2002;58:1434-5

32 Chung OM. MRI confirmed cervical cord injury caused by spinal manipulation in a Chinese patient. Spinal Cord 2002;40:196-9

33 Gamer D, Schuster A, Aicher K, Apfelstedt-Sylla E. Horner's syndrome in dissection of the carotid artery after chiropractic manipulation. Klin Monatsbl Augenheilkd 2002;219:673-6

34 Tseng S-H, Lin S-M, Chen Y, Wang C-H. Ruptured cervical disc after spinal manipulation therapy. Spine 2002;27:E80-E82

35 Licht PB, Christensen HW, Hoilund-Carlsen PF. Is cervical spinal manipulation dangerous? J Manip Physiol Ther 2003;26:48-52

36 Schmitz A, Lutterbey G, von Engelhardt L, von Falkenhausen M, Stoffel M. Pathological cervical practure after spinal manipulation in a pregnant patient. J Manip Physiol Ther 2005;28:633-6

37 Haldeman S, Kohlbeck FJ, McGregor M. Unpredictability of cerebrovascular ischemia associated with cervical spine manipulation therapy. Spine 2002;27:49-55

38 Young Y-H, Chen C-H. Acute vertigo following cervical manipulation. Laryngoscope 2003;113:659-62

39 Hansis ML, Weber B, Smentkowski U, Schrader P. Vorgeworfene Behandlungsfehler im Zusammenhang mit chirotherapeutischen Behandlungen. Orthopade 2004;33:1051-60

40 Oppenheim JS, Spitzer DE, Segal DH. Nonvascular complications following spinal manipulation. Spine J 2005;5:660-7

41 Reuter U, Hamling M, Kavuk I, Einhaupl KM, Schielke E. Vertebral artery dissections after chiropractic neck manipulation in Germany over three years. J Neurol 2006;253:724-30

42 Cagnie B, Vinck E, Beernaert A, Cambier D. How common are side effects of spinal manipulation and can these side effects be predicted? Man Ther 2004;9:151-6

43 Hurwitz EL, Morgenstern H, Vassilaki M, Chiang L-M. Adverse reactions to chiropractic treatment and their effects on satisfaction and clinical outcomes among patients enrolled in the UCLA neck pain study. J Manipulative Physiol Ther 2004;27:16-25

44 Dziewas R, Konrad C, Dräger B, et al. Cervical artery dissectionclinical features, risk factors, therapy and outcome in 126 patients. $J$ Neurol 2003;250:1179-84

45 Rothwell DM, Bondy S, Williams I. Chiropractic manipulation and stroke: a population-based case-control study. Stroke 2001;32:1054-60

46 Smith WS, Johnston SC, Skalabrin EJ, et al. Spinal manipulative therapy is an independent risk factor for vertebral artery dissection. Neurol 2003;60:1424-8

47 Rubinstein SM, Peerdeman SM, van Tulder MW, Riphagen I, Haldeman S. A systematic review of the risk factors for cervical artery dissection. Stroke 2005;36:1575-80

48 Adams G, Sim J. A survey of UK manual therapists' practice of and attitudes towards manipulation and its complications. Physiother Res Int 1998;3:206-27

49 Egizii G, Dupeyron A, Vautravers P. Spinal manipulation: survey of French medical physicians who graduated with the national diploma of osteopathy from Strasbourg University. Ann Readapt Med Phys 2005;48:623-31. DOI: 10.1016/j.annmp.2005.04.013

50 Ernst E. Prospective investigations into the safety of spinal manipulation. J Pain Sympt Manage 2001;21:238-42

51 Kier AL, McCarthy PW. Cerebrovascular accident without chiropractic manipulation: a case report. $J$ Manipulative Physiol Ther 2006;29:330-5
52 Dupeyron A, Vautravers P, Lecocq J, Isner-Horobeti ME. Complications following vertebral manipulation-a survey of a French region physicians. Ann Readapt Med Phys 2002;46:33-40

53 Coulter ID. Efficacy and risks of chiropractic manipulation: what does the evidence suggest? Integ Med 1998;1:61-6

54 Vautravers P. Cervical spine manipulation and the precautionary principle. Joint Bone Spine 2000;67:272-6

55 Mann T, Refshauge KM. Causes of complications from cervical spine manipulation. Aus J Physiother 2001;47:255-66

56 Cagnie B, Vinck E, Cambier D. Side and adverse effects of spinal manipulation. Tijdschrift voor Geneeskunde 2002;58:1317-23

57 Refshauge KM, Parry S, Shirley D, Larsen D, Rivett DA, Boland R. Professional responsibility in relation to cervical spine manipulation. Aus J Physiother 2002;48:171-9

58 Cagnie B, Barbaix E, Vinck E, D'Herde K, Cambier D. Atherosclerosis in the vertebral artery: an intrinsic risk factor in the use of spinal manipulation? Surg Radiol Anat 2006;28:129-34

59 Thanvi B, Munshi SK, Dawson SL, Robinson TG. Carotid and vertebral artery dissection syndromes. Postgrad Med J 2005;81:383-8

60 Killinger LZ. Chiropractic and geriatrics: a review of the training, role, and scope of chiropractic in caring for aging patients. Clin Geriatr Med 2004;20:223-35

61 Haneline M, Triano J. Cervical artery dissection. A comparison of highly dynamic mechanisms: manipulation versus motor vehicle collision. J Manip Physiol Ther 2005;28:57-63

62 Cohn A. A review of the literature regarding stroke and chiropractic. J Vertebral Subluxation Res 2001;4:52-9

63 Wenban A. Critical appraisal of an article about harm: chiropractic adjustment and stroke. J Vertebral Subluxation Res 2001;4:68-74

64 Gotlib AC, Crawford JP, Injeyan HS. Sporadic hypercoagulability, haemodynamic alterations, and manipulation-linked stroke. Clin Chiropractic 2002;9:21-30

65 Haneline M, Croft AC, Frishberg BM. Association of internal carotid artery dissection and chiropractic. Neurol 2003;9:35-44

66 Refisch A, Bischoff P. Manipulation und läsionen der zervikalarterien mehr als zeitliche koinzidenz? Manuelle Med 2004;42:109-18

67 Mirallas-Mart-nez JA. Cerebral vascular complications post-cervical spine manipulation (Spanish). Rehabilitation (Stuttgart) 2003;37:33-8

68 Symons BP, Leonard T, Herzog W. Internal forces sustained by the vertebral artery during spinal manipulative therapy. J Manip Physiol Ther 2002;25:504-10

69 World Chiropractic Alliance. WCA continues to dispel media stroke misinformation. Chiropr J 2002;16:13

70 Filippi MR. Approaches to unsubstantiated criticism: an editorial rejoinder on the stoke (sic) issue. J Vertebral Subluxation Res 2001;4: 65-7

71 Haneline M, Lewkovich G. Critique of the Canadian Stroke Consortium's spontaneous versus traumatic arterial dissection study (SPONTADS). J Am Chiropr Assoc 2004;41:18-21

72 Carson JL, Willett LR. Toxicity of non-steroidal anti-inflammatory drugs: an overview of the epidemiological evidence. Drugs 1993;46:243-8

73 Page J, Henry D. Consumption of NSAIDs and the development of congestive heart failure in elderly patients. Arch Intern Med 2000; $160: 777-84$

74 Ernst E, Pittler MH. Alternative therapy bias. Comp Med 1997;385:480

75 Langworthy JM, le Fleming C. Consent or submission? The practice of consent within UK chiropractic. J Manipulative Physiol Ther $2005 ; 28: 15-24$ 